\title{
0 papel das 0 NGs na construção de políticas de saúde: a Aids, a saúde da mulher e a saúde mental
}

The role of NGOs in designing public health policies: the Aids epidemic, women's health and mental health

Abstract This article evaluates a series of civil society initiatives concerning the design of Brazilian public health policies stemming from the analysis of three cases in which non-governmental organizations played a significant role in the three last decades: the Aids epidemic, women's health and the psychiatric reform. It studies the birth of NGOs in the context of civil society participation in the country, it identifies its distinctive characteristics in relation to other forms of association and it compares their specific paths in the case of Aids, women's health and the psychiatric movement. It points to common dilemmas in the field of NGO s at the end of the 1990's and the need for studies about the participation of civil society organizations in the devel opment of social public policies, specially in the area of public policies concerning violence.

Key words Non-governmental organization, Public health policies, Public security policies
Resumo Este artigo analisa iniciativas da socie dade civil na elaboração de políticas de saúde no Brasil a partir do exame de três casos em que a atuação de organizações não-governamentais teve papel relevante nas três últimas décadas: a epidemia de Aids, a saúde da mulher ea reforma psiquiátrica. Situa o surgimento das O NGs no contexto dos movimentos de participação civil no Brasil, identifica suas características distintivas em relação a outras formas de associação e compara as trajetórias específicas nos casos da Aids, da saúde da mulher e do movimento psiquiátrico. 0 texto indica dilemas comuns ao campo das organizações não-governamentais no final dos anos 90 e aponta a necessidade de estudos sobre a partici pação de organizações da sociedade civil no desenvolvimento de políticas sociais, em especial das políticas contra a violência.

Palavras-chave Organização não-governamental, Políticas públicas de saúde, Políticas de segurança pública 


\section{Sociedade civil e ONG: o fenômeno dos anos 80 e o crescimento dos anos 90}

De acordo com formulação já clássica (Cohen $\&$ Arato, 2000), a sociedade civil é uma esfera de interação social entre a economia e o Estado, composta antes de tudo pela esfera íntima (em especial a família), a esfera das associações (em especial das associações voluntárias), os movimentos sociais e as formas de comunicação pública. Em todo o mundo, após a Primeira Guerra M undial e mais ainda após a Segunda Guerra e a Guerra Fria, instituições da sociedade civil e movimentos sociais passaram a ter papel central nos processos de construção ou de reconstrução da democracia. Santos \& Avritzer (2002) inscrevem na terceira onda de democratização os processos de democratização na América Latina a partir dos anos 70 e 80, juntamente com experiências em países do continente africano e nos países recém-saídos do fascismo no Sul da Europa. A despeito da grande diversidade, a chave comum desses processos nas últimas décadas do século 20 seria 0 surgimento e a proliferação de iniciativas civis voltadas para a construção de democracias participativas, em oposição ao modelo das democracias liberal-representativas predominantes nas sociedades do Norte (2002).

No caso brasileiro, a despeito das objeções ao termo, o fato é que já na primeira metade dos anos 80 as organizações não-governamentais, ou ONGs, ou "ongues", haviam se tornado "uma realidade sociológica" (Fernandes, 1988) e se destacavam entre as experiências organizativas e participativas da sociedade civil. H oje, três décadas após seu surgimento na América Latina, suas atividades cobrem os mais diversos campos da experiência social: do desenvolvimento rural ao controle cidadão de políticas públicas e convenções internacionais (H addad, 2002).

No contexto dos movimentos sociais, há características claramente distintivas que se relacionam ao surgimento e ao desenvolvimento das ONGs, delimitando um campo específico de construção de identidades que as diferencia de outras formas associativas, como os sindicatos, as associações de bairro ou os grupos de base religiosa ou política. Alguns desses aspectos merecem ser destacados, pois serão importantes para compreender os percursos que analisarei na área da saúde.

Seja nos primeiros textos analíticos sobre o fenômeno do surgimento das organizações não-governamentais no Brasil e na América Latina (Landim, 1988; Fernandes, 1988), seja na identificação dos seus dilemas no final dos anos 90 (Landim, 2002; Oliveira, 2002; Dagnino, 2002; Facchini, 2002; Alvarez, 2000; Arantes, 2000; Bebbington, 2002), a questão sobre o que define precisamente a identidade das organizações não-governamentais e o que as distingue de outras formas de organização e participação social e política tem sido uma constante na literatura.

Fernandes (1988) verifica que a trajetória típica das organizações não-governamentais na América Latina foi da igreja católica à secularização; do trabalho assistencial à política social. Landim (1998) situa a constituição do fenômeno das ONGs como tributário da existência, no início dos anos 70, dos Centros de Educação Popular, Assessoria eA poio ou Promoção Social. Estes Centros já apresentavam uma forte noção de "agentes especializados" que se dedicavam a práticas comuns. Segundo esses autores, as ONGs têm como marca distintiva o fato de serem alternativas às práticas institucionais características das universi dades, igrejas e partidos de esquerda (Fernandes, 1988) e, ao mesmo tempo, terem nas universidades, nas igrejas e nos partidos seu triângulo referencial. De fato, as ON Gs não são filantrópicas, por romperem com a noção de caridade, mas estão a serviço do movimento popular (Landim, 1988). Por outro lado, não são acadêmicas, mas as pesquisas e as atividades de formação são seus instrumentos essenciais de intervenção. No triângulo ao qual se opõem e com o qual dialogam, as primeiras organizações a assumirem o nome "não-governamental", no Brasil e na América Latina, foram formadas por uma geração de intelectuais oriundos dos estratos médios das sociedades, que invariavelmente tinham vivido a experiência do exílio ou da luta contra a ditadura.

As tensões advindas do fato de não terem fins lucrativos, sem serem filantrópicas; serem políticas, sem serem partidárias; serem nãogovernamentais, mas, eventualmente, manterem relações de cooperação com governos, constituem parte da dinâmica original de constituição das ON Gs e são, exatamente por isto, pontos de definição de identidades e pertencimentos que se reeditam a cada conjuntura e em cada campo específico. Tais características evidenciam alguns desdobramentos citados a seguir.

Em oposição às práticas típicas da caridade e do assistencialismo, as ONGs valorizam a 
competência técnica. Em outras palavras, elas criam uma categoria de "ativistas profissionais", distantes da militância religiosa, universitária ou partidária, mas guardando conexões com elas. Como indicarei, as exigências de competência específica e de profissionalização da militância irão se acentuando ao longo do tempo.

O fato de as ONGs não se apresentarem como "representativas" (como os sindicatos, as associações e os partidos) associa-se a outras marcas importantes dos anos 70 e 80, como a valorização do pequeno e do local, por um lado, e da autonomia, por outro. Isso explica a ten dência à multiplicação de grupos atuando na mesma área e a recusa sistemática à unificação, à centralização ou à criação de instâncias que ameacem a independência das pequenas entidades. Em alguns casos, como em assuntos do meio ambiente ou aqueles voltados para a prevenção e o monitoramento das políticas contra a Aids, a tendência prolífica foi absolutamente evidente.

Outro aspecto ligado à origem das ONGs e associado a seu desenvolvimento no Brasil e na América Latina é seu diálogo com entidades e organismos internacionais, como a ONU eem particular com os processos estimulados pelo Ciclo de Conferências Sociais da ONU nos anos 90 (Vieira, 2001) - e as fundações e agências privadas de cooperação internacional. Além de uma discussão sobre autonomia diante dosfinanciadores internacionais, o fato de essas relações se manterem muitas vezes sob debates reservados (Landim, 1988) suscitou uma preocupação permanente a respeito da influência das agendas internacionais na construção dos problemas brasileiros. Isso porque, concretamente, as pautas e os financiamentos estrangeiros introduziram, no universo de conceitos e práticas das $\mathrm{ONG}$ s brasileiras, formatos de atuação (por exemplo, sob a forma de "projetos") e prioridades que necessariamente não corresponderam às necessidades e à autonomia local.

A despeito dos problemas advindos dessas relações, segundo Oliveira (2002), as ON Gs e suas relações internacionais foram um importante elemento para colocar a sociedade brasileira em compasso com as novas complexidades e seus paradigmas, gerados primariamente alhures, lembrando que para este campo (nem estatal, nem empresarial) a importação éa contemporaneidade defasada.

De fato, como indicarei nas trajetórias de construção de atuação específica no setor saúde, a presença de organizações não-governa- mentais e suas perspectivas internacionais foram decisivas para inserir pautas contemporâneas ao interior das políticas públicas. Isto se expressa, por exemplo, na "gramática da solidariedade", no caso da Aids; nos "direitos reprodutivos e sexuais", no caso da saúde da muIher; e na "desospitalização", no caso da reforma psiquiátrica.

Em resumo, para analisarmos os casos referentes ao setor saúde é preciso ter em mente as características fundadoras das O N Gs brasileiras e latino-americanas, que são: 1) a valorização da competência técnica, a profissionalização da militância e a especialização; 2) a tendência à multiplicação e à diversificação; 3) a perspectiva internacional; 4) a autonomia em relação ao Estado.

\section{As respostas brasileiras à epidemia de HIV/Aids e as ONGs}

Como se sabe, no início da década de 1980, mais precisamente em 1981, começam a surgir as primeiras matérias na imprensa brasileira sobre o "câncer gay". 0 fato dea notícia ter precedido a doença, isto é, ter chegado antes que o primeiro caso de Aids aparecesse no Brasil, foi chamado por Carrara e M oraes (1985) de "um mal de folhetim". Para Galvão (2000), no seu trabalho de periodização das respostas nãogovernamentais à Aids, o período de 19811982 é crucial para que se entenda a construção das respostas brasileiras. A análise da atuação governamental e civil diante da epidemia é revelada pelo que vários autores nomearam de história social da Aids (Daniel \& Parker, 1990).

Faz parte desse momento inicial a introdução de noções discriminatórias pela mídia - como as de grupos de risco ou a de promiscuidade - , logo alvos de protestos por parte de movimentos sociais que, por outro lado, compreenderam, desde o início, a importância da comunicação e do apelo direto à sociedade. Um dos exemplos dessa dinâmica foi o processo que culminou com o fechamento de bancos de sangue irregulares, a proibição de doações pagas e a implantação de hemocentros mantidos pelo Estado (Carrara \& M oraes, 1985). Adotar uma política de controle de doação e transfusão de sangue, no caso brasileiro e em particular no Estado do Rio de Janeiro, era uma providência há muito planejada, mas sistematicamente obstada por proprietários de bancos de sangue e empresários da saúde. 0 escândalo provocado 
pela divulgação de que hemoderivados estavam contaminados com o HIV foi decisivo para que uma política de controle do sangue finalmente se implantasse, com o apoio de associações de hemofílicos, militantes do movimento social, pesquisadores e médicos ligados à reforma sanitária. Em outras palavras, "o mal de folhetim" expressa uma primeira e muito importante característica tipicamente contemporânea do enfrentamento da Aids, e central no caso brasileiro: os meios de comunicação passaram a exercer um importante papel como "mediadores" de forças situadas na sociedade civil, nos setores privados e nos poderes públicos.

Um momento posterior, segundo periodização de Galvão (2000) , ocorreu entre 1985 e 1991, quando foram criadas as primeiras organizações dedicadas exclusivamente à Aids. Esta fase consolidou um padrão de intervenção da sociedade civil, que foi responsável, em boa medida, pela história da doença no Brasil. Entre 1985 e 1989, foram criadas três organizações paradigmáticas das ações que se multiplicam nos anos seguintes: Gapa, Abia e Pela Vidda.

0 Grupo de Apoio e Prevenção à Aids ( Gapa) foi criado em 1985, em São Paulo, por iniciativa de vários atores: militantes de esquerda, pessoas ligadas ao movimento homossexual, advogados, intelectuais e médicos que atuavam no programa estadual de atenção à Aids. Esse movimento celebrizou um novo tipo de discurso com a campanha "Transe numa boa". Também fundou o primeiro serviço de assessoria jurídica para pessoas com HIV/Aids, que serviu de modelo para outras entidades, constituindo um campo de atuação que posteriormente foi consolidado como advocacy.

A Associação Brasileira Interdisciplinar de Aids (Abia) foi fundada em 1986, influenciando muito fortemente as ações anti-Aids: 1) pelo seu pertencimento decisivo ao universo das "ONGs"; 2) por suas articulações com as políticas internacionais de Aids e 0 acesso a financiamentos de agências internacionais de cooperação; 3) por sua perspectiva política no trabalho de pressão, cobrança e monitoramento das ações governamentais de prevenção e de tratamento; 4) pela decisão de atuar no campo da mídia; 5) pela preocupação com a produção de conhecimentos sobre a epidemia e com 0 desenvolvimento de projetos piloto de prevenção em segmentos específicos.

Alguns dos elementos marcantes do desenvolvimento das ON Gs tornam-se mais acentuados com o surgimento, em 1989, da primeira organização de pessoas com HIV/Aids. O Grupo Pela Valorização, Integração e Dignidade do Doente de Aids (Pela Vidda) foi criado por Herbert Daniel, então diretor da Abia, que se descobriu portador do vírus. Seu fundador tecia um discurso na primeira pessoa: Estou enviando a esses burocratas, que nunca viram um doente de Aids, notícias daqui. Da vida. Eles estão moribundos, no lamaçal do governo Sarney. Eu estou vivo. E, como milhares de brasileiros com Aids, exijo uma mudança de rumo na política sobre Aids. Que seja fundada na compreensão do problema epidêmico e guiada pela solidariedade (Daniel, 1988). Estimulados por slogans como o da organização norte-americana Act Up, adotado mundialmente pelo ativismo contra a Aids ( silence = death), grupos de pessoas vivendo com HIV/Aids passaram a representar uma importante novidade, alterando, em boa medida, o paradigma de "assessoria" e de "apoio" que tinha predominado na tradição dos Centros nos anos 70 e nas ON Gs sociais dos anos 80 no Brasil.

A multiplicação de organizações baseadas nesses três grandes tipos (de apoio e de advocacy; de pressão política e de pesquisa aplicada; e de pessoas vivendo com Aids), ocorreu, nos anos seguintes, em escala extraordinária. Constituiu-se um campo político e institucional que passou a ser nomeado de O N G/Aids. Teórica e historicamente, a delimitação desse campo foi polêmica. Alguns analistas passaram a considerar que deste segmento fazem parte apenas as organizações dedicadas ao ativismo contra a Aids e criadas para este fim (Câmara $\&$ Lima, 2000). Outros (Solano, 2000) preferiram chamar de ONG/Aids todas as organizações que exerciam alguma atividade no campo de luta conta e epidemia, incluindo aí grupos feministas, homossexuais, religiosos, educacionais, e ainda entidades cuja existência passou a ser estimulada pela militância contra a Aids, como os grupos de "profissionais do sexo" ou de "usuários de drogas". Outros incluíram ainda nesse campo, mas com uma identidade diferenciada, as "casas de apoio", instituições que se tornaram emblemáticas das instituições e ações de solidariedade, como a casa criada pela travesti Brenda Lee, em São Paulo, e a Sociedade Viva Cazuza, no Rio de Janeiro (Galvão, 2000). Levantamentos realizados pelo Programa Nacional de DST/Aids do M inistério da Justiça registraram a existência de 402 O NGs trabalhando com Aids em 1995; 587 em 1998; e 444 em 1999 (Solano, 2000). 
No plano político, é importante ter em mente que o desenho inicial dos padrões de mobilização da sociedade civil de respostas à Aids foram determinados pela conjuntura de intensa mobilização do contexto da democratização. Os embates entre ONG e o governo federal predominaram durante o período Sarney (1986-1990) até o final do governo Collor, em 1992. Analisando o papel político das organizações não-governamentais de prevenção da Aids e sua relação com o Estado, Teixeira (2002) conclui que haveria um certo "uso estratégico" da pressão exercida pelas ON Gs por parte dos setores governamentais: no caso da ABIA e de outras ON G-Aids, que mantêm uma relação de pressão sobre o governo, o acompanhamento que elas fazem é essencial para a aplicação dos programas deAids.

É necessário, ainda, assinalar dois aspectos relacionados à construção de respostas à Aids no Brasil nos quais a presença das ON Gs foi afetada ou teve importante papel: o financiamento do Banco M undial dispensado ao governo brasileiro, em 1992/1993, e a concessão de acesso gratuito e universal, na rede pública da saúde, aos medicamentos anti-retrovirais, em 1996.

O financiamento do Banco Mundial concedido ao Brasil para o controle da epidemia representou, segundo documentos do próprio Banco, situar o Brasil como um test case de políticas da instituição para a área de saúde e especificamente para a Aids. 0 montante dos recursos e o fato de que o projeto foi a principal fonte de investimentos do país para controlar a epidemia tornaram o empréstimo um ponto de inflexão na trajetória das políticas para a Aids. Analistas observam que a partir do processo de negociação do empréstimo, o governo brasileiro elaborou o Projeto de Controle de AIDS e DST (ou AIDSI), que representou um "divisor de águas" nas políticas tanto governamentais quanto comunitárias de saúde relacionadas à gestão da epidemia (Galvão, 2000). Isto porque um item importante da negociação do empréstimo, vital para a centralidade das ONGs no contexto político das ações de prevenção e tratamento, foi a exigência do envolvimento dessas entidades, especialmente por serem vistas como mais eficientes para atingir os mais pobres e os mais resistentes, como homossexuais, usuários de drogas e profissionais do sexo (Galvão, 2000). Alguns autores, a propósito do papel que as agências multilaterais atribuem às $O N G s$, chamam a atenção para o fato de que elas têm sido conceituadas como atores de desenvolvimento e não tanto como fenômenos sociais que devem ser entendidos em relação a um conjunto de outras relações sociais (Bebbington, 2002). 0 fato relevante é que $\mathrm{ONG}$ /Aids passaram a contar com recursos do programa nacional para desenvolver programas de prevenção e apoio, sendo esta a fonte essencial de sobrevivência de várias entidades, colocando em jogo a autonomia dessas iniciativas, como indicarei adiante.

Em relação ao tratamento dos portadores sintomáticos do HIV, contrariando as recomendações não só do Banco Mundial, mas da OM S e da OPS de que os países pobres devem investir os recursos na prevenção de novos casos, e não no tratamento dos doentes, a partir de 1996 o Brasil passou a dar acesso, de forma gratuita e universal, na rede pública de saúde, aos medicamentos anti-retrovirais, nisso que Galvão chama de uma das ações mais espetaculares do programa nacional de Aids (2000).

A implementação da lei 9.313, de novembro de 1996, que tornou obrigatório o fornecimento de medicamentos para Aids, fortaleceu os órgãos públicos perante a sociedade, a mídia e al guns fóruns internacionais, de forma que 0 país assumiu uma batal ha internacional para garantir a continuidade da produção de medicamentos para Aids. Galvão (2002b) chama a atenção, contudo, para o fato de que esse capítulo, longe de estar encerrado, mantém abertas questões cruciais: em 2002, mais de 100 mil pessoas recebiam medicamentos para a Aids, sendo que isso representava aproximadamente $10 \%$ das pessoas que globalmente recebem medicamentos. Acresce-se a isso que mais da metade dessas pessoas, no Estado de São Paulo, estavam desempregadas, em 2001. A articulação desses el ementos levanta dúvidas sobre 0 futuro dessa conquista.

Seja como for, parece não haver dúvida de que, no caso da epidemia de Aids, as ONGs desempenharam papel importante para 0 desenvolvimento de políticas de prevenção e assistência. Assim, a presença acentuada da sociedade civil no contexto das respostas à epidemia contribuiu decisivamente para a construção do que alguns analistas chamam a especificidade da história da Aids brasileira (Galvão, 2000; Daniel \& Parker, 1990). Também fica claro que essa participação se deu, em grande medida, dentro do paradigma típico das organizações não-governamentais e das características de especialização, competência técnica, profissio- 
nalização da militância, tendência à proliferação de iniciativas e de articulações internacionais.

Em relação à autonomia diante do Estado, a trajetória das ON Gs é marcada por dois momentos distintos. Nos anos 80, de franca oposição. Nos anos 90, predominaram relações de cooperação, inclusive com um trânsito intenso de militantes de ONG passando a gestores de programas governamentais. Como indicarei na última parte deste artigo, as críticas de que "cooperação" e "parceria" tornaram-se "cooptação", "prestação de serviços" e "substituiçãa do Estado" serão constantes não só em relação à forma de atuação no enfrentamento da Aids, mas em geral, no campo das ONGs. Essa dinâmica de certa "promiscuidade" passa a constituir-se num dilema central nas relações entre ONG, Estado e mercado na década atual.

\section{Saúde da mulher, direitos reprodutivos e direitos sexuais}

0 chamado feminismo brasileiro da "segunda onda" (Schumaher \& Brazil, 2000) surgiu em meados da década de 1970 e a expressão serviu para diferenciá-lo da tradição de luta pelo direito ao voto do final do século 19.0 feminismo contemporâneo nacional sofreu os impactos das idéias de Simone de Beauvoir e Betty Friedan, e de palavras de ordem internacionais, como "nosso corpo nos pertence" e "diferentes, mas não desiguais". A nova onda se desenvolveu em pleno regime militar, contra a ditadura, afrontando a supremacia masculina, a violência sexual e afirmando o direito ao prazer.

0 ano de 1975 foi um marco da construção deste campo. Nesse período aconteceram: a reunião anual da SBPC, que realizou um encontro considerado histórico sobre o tema muIher; a criação da primeira organização feminista do Centro da Mulher Brasileira, no Rio de Janeiro; o Encontro para o Diagnóstico da M uIher Paulista e a organização do M ovimento Feminino pela Anistia. Nos anos seguintes seriam criados diversos grupos em São Paulo, no Rio, no Distrito Federal e no Nordeste, abrigando não só múltiplas formas de organização, mas novas especificidades, como grupos de trabalhadoras rurais e sindicais, de produtoras culturais, de educadoras populares, de mulhe res lésbicas, de prostitutas e de empresárias.

Nos anos 80 houve vários Encontros Nacionais Feministas, a criação do Conselho Nacio- nal de Direitos da Mulher (CNM D), em 85, ea multiplicação de conselhos e coordenações municipais e estaduais. $\mathrm{Na}$ Constituinte de 1988, o chamado lobby do batom aprovou mais de $80 \%$ das reivindicações na área dos direitos da mulher. Para o movimento feminista, os anos 90 foram dedicados à participação nas Conferências da ONU e à consolidação de redes, sendo uma das mais importantes a Rede Nacional Feminista de Saúde e Direitos Reprodutivos (RedeSaúde).

Estima-se que nessas três décadas de feminismo contemporâneo mais de 1.000 grupos foram organizados no País, atuando em diferentes setores: em partidos políticos, em estruturas do Estado, dos sindicatos, das associações de moradores, das universidades, em grupos autônomos, em instâncias de controle social e em ON G (Schumaher \& Brazil, 2000). Ressalta-se, nesse universo, a multiplicidade e a riqueza de naturezas associativas. Comparativamente ao campo das ONG/Aids, os movimentos de mulheres são mais heterogêneos e as relações com a formulação de políticas públicas são menos precisas. No entanto, a influência e a difusão de "idéias feministas" por toda a sociedade, inclusive entre elaboradores e gestores de políticas, tenderam a ampliar os processos de demanda, de pressão e de diálogo com os poderes públicos.

Ao longo das décadas da nova onda, algumas questões passaram a aglutinar as diversas organizações às quais mulheres se filiavam, entre elas a luta pela saúde, os direitos reprodutivos e a descriminalização do aborto. Esses três pontos passaram a compor uma agenda de interseção com o que chamarei de políticas de "saúde da mulher".

Segundo Bonan (2002), foi em 1984, no IV Encontro Internacional Mulher e Saúde, em Amsterdã, que entidades feministas consagraram a expressão "direitos reprodutivos", para significar uma área de reflexão e produção de conhecimentos sobre saúde, sexualidade, reprodução e integridade corporal. "Direitos reprodutivos" tornou-se um marco discursivo e conceitual da vanguarda dos movimentos de mulheres desde então. Dez anos depois, na Conferência Internacional sobre População e Desenvolvimento, no Cairo, em 1994, e na Conferência M undial da Mulher, em Beijing, em 1995, a terminologia "direitos sexuais e reprodutivos" se consagrou globalmente, mas não consensualmente: a plataforma de direitos reprodutivos foi amplamente majoritária nesse 
evento. Porém, a plataforma de direitos sexuais tornou-se alvo de conflitos entre feministas e um bloco de países conservadores.

No Brasil, muito antes que a terminologia "direitos reprodutivos e sexuais" se consagrasse, a participação dos movimentos feministas em instâncias do Estado já havia se tornado importante por meio da criação do Programa de Assistência Integral à Saúde da Mulher (PAISM ), cujo início se deu em 1983. No contexto das disputas pelas políticas de controle de natalidade, de um lado, atores pró-controle demográfico contavam com a simpatia de setores militares, empresariais e tinham forte influência no Parlamento. No outro lado, num ambiente ainda tímido de transição política, feministas e sanitaristas se reapropriavam do tema, introduzindo interpretações e novas propostas a partir de uma filosofia de emancipação da mulher. Nesse cenário, o PAISM foi comemorado como uma derrota das forças controlistas. $\mathrm{Na}$ formulação do programa, o Estado (tradicionalmente omisso nas relações entre entidades privadas de planejamento familiar e população) assumia responsabilidades na área da regulação da fecundidade e as delegava ao setor da saúde, onde a presença de médicos envolvidos com a reforma sanitária era notória.

Um dos efeitos do processo de elaboração do PAISM foi o estreitamento de laços entre os movimentos feministas e o movimento sanitarista. Além de os movimentos de mulheres terem assumido bandeiras da reforma sanitária e terem se envolvido na luta pela construção do SUS, a aproximação entre ambos os movimentos aproximou as feministas dos setores médicos ligados às cátedras de ginecologia e obstetrícia de universidades públicas. Esse saudável encontro colocou as questões de gênero na pauta das instituições públicas de saúde (Bonan, 2002).

Bonan aponta outros três processos políticos significativos para os movimentos feministas na área de saúde da mulher, além do PAISM, na década de 1980.0 primeiro pode ser caracterizado pelo embate em torno dos "direitos de reprodução humana", em especial pelas denúncias que envolveram a pesquisa com o anticoncepcional Norplant e sua cassação, em 1986, pela Comissão Nacional de Estudos da Reprodução Humana. O segundo está relacionado às campanhas pelo direito ao aborto. E o último à luta contra a esterilização cirúrgica indiscriminada de mulheres.

A polêmica do Norplant ajudou a trazer para o centro dos debates, através da mídia, as preocupações, os princípios e o discurso feminista, permitindo aprofundar o diálogo entre 0 movimento de mulheres, autoridades de saúde e médicos. A discussão sobre o aborto, por sua vez, reconfigurou as relações entre as feministas e outros setores sociais que haviam sido aliados nas lutas contra a ditadura, como setores da esquerda e o próprio campo mais amplo dos movimentos de mulheres. No âmbito de lutas contra as esterilizações cirúrgicas indiscriminadas, os movimentos de mulheres obtiveram vitórias simbólicas, pois o interesse de organizações privadas de controle da natalidade se reduziram na medida em que caíam as taxas de fecundidade. Não obstante não terem sido confirmadas as denúncias de esterilização em massa de mulheres negras, a CPI da Esterilização Cirúrgica, instalada em 1991, teria ajudado a ampliar o debate político sobre sexualidade e reprodução, iniciado com o processo de construção do PAISM.

Nos anos 90 foram criadas ONG importantes, como a Cidadania Estudo, Pesquisa, Informação e Ação (Cepia), o grupo Geledés de Mulheres Negras e a Rede Nacional Feminista de Saúde e Direitos Reprodutivos (RedeSaúde). No mesmo período, os movimentos se aprofundaram e se politizaram: fincaram presença na esfera parlamentar aumentando as bancadas femininas. Ao mesmo tempo evidencia-se o crescimento, a especialização e a profissionalização de O N Gs dedicadas exclusivamente ao acompanhamento legislativo, como é o caso do Centro Feminista de Estudos e Assessoria (Cfemea). Simultaneamente à atuação em políticas-fim relacionadas a direitos reprodutivos e sexuais, a década de 1990 também consagrou a participação de representantes feministas nos conselhos de saúde e em outras instâncias mediadoras de políticas públicas de saúde. Os novos formatos institucionais, as discussões internacionais, a presença crescente na esfera parlamentar e em outras instâncias de formulação de políticas movem os movimentos feministas dos anos 90 para o terreno da especialização, da competência técnica, da internacionalização e das redes de ONGs.

Essas novas características presentes nos anos 90 são tão acentuadas que Alvarez (2000) vai nomeá-las ON Gguização dos feminismos, identificando processos semel hantes nos movimentos latino-americanos. Analisando a participação de delegadas da América Latina na Conferência Mundial da Mulher (Beijing, 1995), a autora identificou outras quatro tendências 
que se combinam para revelar novos formatos políticos das intervenções feministas: 1) a extraordinária proliferação ou multiplicação dos espaços e lugares em que as mulheres que se consideram feministas atuam e por onde circulam discursos feministas; 2) a rápida absorção dos discursos e agendas feministas pelas instituições culturais da sociedade, dos Estados e do establishment internacional do desenvolvimento; 3) a articulação das feministas em redes internacionais (de militantes individuais, de ON Gs ou de especialistas) filiando os feminismos latino-americanos à "sociedade civil global"; 4) a transnacionalização dos discursos e das práticas que haviam sido forjadas localmente nos anos 70 e 80.

As sugestões de Alvarez reforçam a tese de que a participação dos movimentos feministas na construção de políticas de saúde da mulher foi decisiva, havendo duas grandes tendências: na década de 1980, a participação de formato mais espontâneo, heterogêneo e multifacetado (influenciado pelos padrões do movimento de reforma sanitária, especialmente em sua característica de valorizar a ocupação das "brechas" abertas mesmo durante o regime militar); nos anos 90, num formato próximo ao da atuação das ONG/Aids: passam a predominar ONGs feministas transnacionalizadas, altamente profissionalizadas e tematicamente especializadas (Alvarez, 2000).

A experiência mostra que se essas características tendem a aumentar extraordinariamente a eficiência das ações, trazem vários riscos. Um deles é a perda de referência das aspirações de mulheres que estão fora do campo das ONGs. Não se deve perder de vista que entre as várias agendas feministas, muitos grupos populares de mulheres, desde os anos 70, tinham entre suas prioridades as temáticas da saúde por viverem diretamente 0 drama das condições precárias de atendimento, eque "saúde" foi o mote através do qual se aproximaram feministas de classe média, mulheres pobres, médicos e ativistas da reforma sanitária (Bonan, 2002).

Por último, se é verdade que no campo de saúde da mulher, nos anos 90, a participação da sociedade civil desenhou processos similares aos da Aids, não se deve esquecer que no caso desta última, o fato de parte dessa militância ser constituída por portadores do HIV/Aids e, portanto, de usuários dos sistemas de saúde, assegura maior proximidade entre ONG e demandas sociais difusas da coletividade. Essa característica não é tão evidente no caso da saúde da mulher.

\section{0 movimento por uma sociedade sem manicômios e a reforma psiquiátrica}

Como nos casos anteriores, as políticas para a saúde mental foram objeto de vivo interesse de atores sociais que a influenciaram através de atuações externas à gestão sanitária nas últimas três décadas, determinando, em grande medida, sua trajetória. Também em comum com os dois outros casos, verifica-se na área da saúde mental a influência de movimentos internacionais, tanto teóricos como pelas experiências práticas de novos model os de atendimento que se desenvolviam nos Estados Unidos e na Europa.

Amarante define reforma psiquiátrica como um processo histórico de formulação crítica e prática, que tem como objetivos e estratégias o questionamento e elaboração de propostas de transformação do modelo clássico e do paradigma da psiquiatria (1995). No caso brasileiro esse processo é tributário dos debates teóricos e das experiências que constituem o ideário da "nova psiquiatria" (Venancio, 1990), ou seja, é oriundo da tradição da psiquiatria crítica brasileira, que teve como expoentes Luiz Cerqueira, Oswaldo Santos e Hélio Pellegrino, e de correntes reformadoras de repercussão internacional, como a comunidade terapêutica de $M$ axwell Jones, a psiquiatria institucional de Tosquelles, a psiquiatria de setor de Bonnafé, a psiquiatria preventiva de Caplan, a antipsiquiatria de Laing e Cooper e, mais tarde, a psiquiatria na tradição de Basaglia e das experiências de Gorizia e Trieste (Amarante, 1995).

No Brasil, o processo se iniciou no final da década de 1970, no contexto político de luta pela democratização. 0 principal marco de sua fundação é a chamada "crise da Dinsam" (Divisão Nacional de Saúde M ental), que eclode em 1978. Os profissionais da área denunciavam as péssimas condições da maioria dos hospitais psiquiátricos do M inistério da Saúde no Rio de Janeiro e vários foram demitidos. No mesmo ano, no $V$ Congresso Brasileiro de Psiquiatria, uma caravana de profissionais da saúde demitidos no processo de lutas da Dinsam divulgou o M anifesto de Camboriú e marcou o I Encontro Nacional de Trabalhadores em Saúde M ental, realizado em São Paulo, em 1979. Neste processo surge o principal protagonista da reforma psiquiátrica brasileira, o 
M ovimento dos Trabalhadores em Saúde M ental (M TSM).

É crucial para nossa análise assinalar características do nascimento e da constituição desse novo personagem, O M STM . 0 movimento surge apoiado tanto no Centro Brasileiro de Estudos da Saúde (Cebes), que havia sido fundado em 1976 e que reunia o pensamento crítico que em grande medida lideraria a reforma sanitária, como no M ovimento de Renovação M édica (Reme) ligado ao Sindicato dos M édicos. 0 fato de o movimento de reforma psiquiátrica cunhar a expressão "trabal hadores em saúde mental" indicava a tentativa de escapar do sentido mais corporativo de "categoria", sinalizando que não se tratava apenas da reunião de médicos. 0 segundo sentido de "trabal hadores" (e não "servidores") era demarcar uma categoria "supraprofissioanal" (Venancio, 1990). A expressão trabal hadores também assinalava um sentido ideológico de filiação à esquerda, que predominava no Cebes e no Sindicato dos M édicos. De fato, esses dois grandes grupos articulados em torno do Cebes e do Reme configuraram a união da sociedade civil em torno da problemática da reforma do setor saúde.

0 tema que atravessou a formação ea história do M TSM diz respeito a seu formato e seu grau de institucionalidade. Segundo Amarante (1995), desde sua criação, o debate sobre institucionalizar ou não o movimento surge em inúmeras reuniões, assembléias e encontros. Às vantagens da institucionalização (a possibilidade de ter uma sede, secretaria, fundos e agilidade administrativa) sistematicamente eram opostos os riscos como a burocratização, 0 enrijecimento, a perda de flexibilidade e a cronificação das lideranças. Além disso, o MTSM se autocaracterizava por ser "múltiplo e plural", isto é, por articular não só profissionais de todas as categorias, mas simpatizantes não-técnicos. Talvez por inspiração das bandeiras de "desinstitucionalização" do saber e das práticas psiquiátricas, o M TSM foi o primeiro movimento em saúde com participação popular, não sendo identificado com um movimento ou entidade de saúde, mas pela luta popular no campo da saúde mental (...) (Amarante, 1995). N esse sentido, 0 MTSM prefigura, de certa forma, o formato organizacional que predominou no movimento de reforma sanitária e se distingue tanto das ONG/Aids como das várias formas de intervenção dos movimentos de mulheres na elaboração de políticas de sexualidade e direitos reprodutivos, especial mente as verificadas nos anos 90 .
Um outro debate permanente acompanhou a longa trajetória do M TSM : participar ou não das instituições psiquiátricas que se desejava modificar; participar ou não da gestão política de saúde mental, nos cargos de chefia e coordenação. Houve no movimento um intenso debate entre estratégia de ocupação de cargos nos órgãos estatais como tática de mudança por dentro versus "cooptação" (Amarante, 1995). Embora tenha sido predominante a tendência de aproximação, ingresso e ocupação de postos no Estado, nessa ocasião o movimento dividiu-se em duas linhas: uma chamada institucional, outra chamada sindical.

No intenso processo que se seguiu a esta fase, é importante sublinhar alguns eventos, como o I Encontro de Coordenadores de Saúde M ental da Região Sudestee o I Congresso de Trabal hadores em Saúde M ental, em 1985, já numa conjuntura francamente democratizante e com parte significativa dos postos de chefia de programas estaduais e munici pais de saúde mental sob a condução de fundadores e ativistas do M TSM . A 8a Conferência Nacional de Saúde, com 176 delegados eleitos nas conferências estaduais, usuários e outros segmentos representativos é vista como um marco e um ponto de inflexão do processo, pois a partir dela o movimento assumiu o lema "por uma sociedade sem manicômios" e criou o Dia de Luta Antimanicomial (Venancio, 1990). Em particular, nessa trajetória, é importante assinalar a vinda ao Brasil, em 1986, de Franco Rotelli, então secretário geral da Rede Internacional de Alternativas à Psiquiatria, e diretor do Serviço de Saúde M ental de Trieste, desde a saída de Franco Basaglia.

Segundo Amarante, a partir do evento conhecido como Congresso de Bauru, a partir da criação de experiências institucionais e associativas alternativas em São Paulo, Santos e Bauru e da elaboração do projeto de lei que mais tarde ficou conhecido como Projeto Paulo Delgado, ocorreu uma ruptura com o processo anterior da reforma psiquiátrica. Passou a haver 0 reconhecimento da inviabilidade de transformação meramente "por dentro" das instituições e a retomada das perspectivas desinstitucionalizantes e basaglianas do início do M TSM . A partir de então, promoveu-se a abertura do movimento para novos atores, como as associações de usuários e familiares. A partir de 1987, o M TSM passou a denominar-se M ovimento por uma Sociedade sem M anicômios. Em 1992, em Braślia, foi realizada a decisiva 2a 
Conferência Nacional de Saúde M ental, com 1.500 participantes. Os desafios da desospitalização continuaram ao longo da década, inclusive a partir de uma importante frente parlamentar e do desenvolvimento de experiências alternativas de atendimento como hospital-dia.

0 que há de peculiar na trajetória de participação na reforma psiquiátrica é o percurso inverso ao das duas outras áreas analisadas: 0 movimento de reforma psiquiátrica inicialmente surge da sociedade e se dirige rapidamente às instituições e à gestão interna da saúde para, apenas numa segunda etapa - , já num momento avançado da democratização - retomar o diálogo com outros atores sociais e com novas experiências.

\section{Desafios e perspectivas}

As perguntas sobre o futuro das $O N$ Gs não são novas, sendo praticamente simultâneas à constituição deste campo (Fernandes, 1988). M as, no final dos anos 90 , pelo menos quatro aspectos tinham alterado profundamente o cenário nacional e internacional no qual a participação da sociedade civil havia se desenvolvido: a globalização econômica e cultural; a reforma do Estado; a hegemonia de políticas neoliberais; 0 aprofundamento da degradação social daí decorrente (H addad, 2002). Para Evelina Dagnino (2002), o efeito dos ajustes estruturais constitutivos das políticas neoliberais determinou dificuldades significativas no ritmo da democratização. M as, se o agravamento das dificuldades sociais e econômicas é um efeito amplamente reconhecido na implementação dessas políticas, menos notórias são as conseqüências sobre a capacidade de organização e mobilização políticas da sociedade civil, especialmente dos setores populares e das classes médias, duramente afetados pelo desemprego e pela recessão econômica.

Um dos dilemas das organizações da sociedade civil, em particular do campo das ONGs, é manter a defesa do fortalecimento de suas formas associativas e organizativas sem confundi-las com a lógica privatista e de minimalismo estatal de cunho liberal, tão presentes no campo da saúde (implícitas, por exemplo, nas recomendações de apoio às ON Gs por serem menos onerosas, mais ágeis e mais eficazes do que o Estado para a realização de certas tarefas públicas). Pereira \& Grau (1999) caracterizam essa tensão definindo duas grandes áreas de concentração de esforços das organizações públicas não-estatais: por um lado, o controle social das políticas públicas e, por outro, 0 compromisso com a produção de bens e serviços. Para os autores, algumas organizações (como as ONGs) têm missões combinadas de participar do controle social e produzir serviços. As organizações de ajuda ou caridade não assumem o compromisso do controle social. E as organizações de serviços públicos não-estatais (Ospnes), geralmente estruturadas em forma de fundações de direito privado e associadas ao movimento de reforma da administração pública, são essencialmente produtoras de serviços sociais de educação e saúde, com escassa experiência de cooperação voluntária.

Um outro dilema no campo das organizações não-governamentais é a ênfase na especialização, na profissionalização e na hipereficiência. Essas características das O N Gs, acentuadas ao longo da década de 1990, podem afastar não só as organizações da sociedade civil das aspirações populares, como levar a um questionamento de sua própria natureza. Segundo Oliveira, a condição principal para as ONGs da democratização manterem-se como integralmente demiúrgicas, vozes do novo, é a radicalidade da denúncia, menos que a modernidade da competência (2002).

\section{Sociedade civil e segurança pública}

Não obstante suas marchas e contramarchas, a reforma sanitária e a consagração de seus princípios na Constituição de 1988 configuram o que Faveret e Oliveira assinalaram como a primeira experiência brasileira de uma política social universalizante, configurando uma ruptura pioneira no padrão de intervenção estatal no campo social moldado na década de 30 e até então intocado em seus traços essenciais (1990).

Considerando seu caráter exemplar e paradigmático para outras políticas sociais, sugiro que o exame das dinâmicas de participação da sociedade civil na construção de políticas de saúde, em especial das trajetórias de ONG, na forma de "estudos de caso", pode vir a ser mais explorado do que tem sido até o momento. Tais casos são um campo fértil de análise e de inspiração para iniciativas de indução e atração da sociedade civil onde essa presença é historicamente menos densa, como é o caso da segurança pública.

A despeito do relativo interesse de estudos sobre violência, verifica-se que a extrema escas- 
sez de experiências de participação social na elaboração de políticas de segurança pública e, por sua vez, de investigações analíticas sobre esses processos, tem sido um dos obstáculos estruturais à democratização e à modernização da polícia e dos órgãos de segurança (Soares, 2001). A exceção a esta regra é a reivindicação e a conquista, no início da década de 1980, de serviços especializados em atendimento a mulheres vítimas de violência na esfera da polícia. As Delegacias Especializadas de Atendimento à Mulher (DEAMs) criadas em diversos Estados foram resultantes de esforços e iniciativas dos movimentos feministas e de mulheres. Sob o lema "Quem ama não mata" foram realizadas campanhas, lançados seriados na televisão e requerida uma CPI. Em contraste com os resultados obtidos no início dos anos 80, as ONGs e redes ligadas às articulações de mulheres reduziram drasticamente a importância da temática da violência nas agendas do movimento no final dos anos 80 e durante os anos 90, ficando este campo reduzido a entidades dedicadas exclusivamente a atender vítimas de violência doméstica. 0 movimento de mulheres tornou-se virtualmente ausente do atual debate sobre democratização da polícia e reforma da segurança. Sugiro que compreender a história e as razões da suspensão dos interesses feministas nesse campo e compará-las aos percursos na área da saúde pode ser especialmente importante para a compreensão das dinâmicas das experiências de participação de organizações não-governamentais na elaboração de políticas sociais.

Em 1999, a Secretaria de Segurança do Rio de Janeiro criou projetos para estimular participação de organizações não-governamentais no acompanhamento de políticas de segurança, dentro de programas de proteção de minorias. Entre eles estavam o Centro de Referência de Proteção das Minorias Sexuais, o Centro de Referência de Luta contra o Racismo, o Centro de Referência da Criança e do Adolescente e o Centro de Referência de Proteção Ambiental (Ramos, 2002). Cada Centro de Referência desenvolveu diferentes estratégias de ação e atividades. Via de regra, os Centros "inauguraram" relações entre movimentos sociais e a área de segurança pública no Rio de Janeiro. O rganizações não-governamentais ligadas ao movimento homossexual, ao movimento negro e ao movimento ambiental estabeleceram conexões não experimentadas anteriormente, ao menos na modalidade de participação direta no planejamento e monitoramento de programas de segurança. Em especial, os temas do racismo e da homofobia, além da violência contra a mulher, mobilizaram atores que tiveram intensas experiências de participação em políticas de saúde. A análise das experiências de entidades do movimento de mulheres, do movimento negro e do movimento homossexual no campo da segurança pública podem ser extremamente enriquecidas, quando sublinhadas as diferenças desses grupos com suas experiências na área da saúde.

\section{Referências bibliográficas}

Alvarez SE 2000. A "globalização" dos feminismos latinoamericanos, pp. 383-426. In SE Alvarez, E Dagnino \& A Escobar (orgs.). Cultura e política nos movimentos sociais latino-americanos. Editora U FM G, Belo Horizonte.

Amarante P 1994 (org.). Psiquiatria social e reforma psiquiátrica. Fiocruz, Rio de Janeiro.

Amarante P 1995 (coord.). Loucos pela vida: a trajetória da reforma psiquiátrica no Brasil. Fiocruz, Rio de Janeiro.

Bebbington A 2002. Reflexões sobre a relação norte-sul na construção de conhecimentos sobre as ON Gs na América Latina, pp. 93-118. In S Haddad (org.). ON G e universidades: desafios para a cooperação na América Latina. Editora Fundação Peirópolis, São Paulo. 
Bonan C 2002. Reflexividade, sexualidade e reprodução. Processos políticos no Brasil e no Chile. Tese de doutorado. Instituto de Filosofia e Ciências Sociais, Universidade Federal do Rio de Janeiro, Rio de Janeiro.

Câmara C \& Lima RM 2000. Histórico das ONGs/Aidse sua contribuição no campo das lutas sociais. Direitos humanos, cidadania eAids. Cadernos Abong 28:29-74.

Carrara S \& M oares C 1985. Um mal de folhetim. Comunicações do ISER 17: 20-26.

Cohen JL \& Arato A 2000. Sociedad civil y teoria política. Fondo de Cultura Econômica, M éxico.

Dagnino E 2002 (org.). Sociedade civil e espaços públicos no Brasil. Editora Paz e Terra, São Paulo.

Daniel H \& Parker R 1990. Aids, a terceira epidemia: ensaios e tentativas. I glu Editora, São Paulo.

Daniel H 1989. Vida antes da morte/ Life before death. Tipografia Jabuti, Rio de Janeiro.

Facchini R 2002. Sopa de letrinhas? M ovimento homossexual e produção de identidades coletivas no anos 90. Dissertação de mestrado. Departamento de Antropologia Social, Universidade Estadual de Campinas, São Paulo.

Faveret P \& Oliveira PJ 1990. A universalização excludente: reflexões sobre as tendências do sistema de saúde. Planejamento e Políticas Públicas 3:139-162.

Fernandes RC \& Carneiro LP 1991. NGOs in the nineties. A survey of their Brazilian leaders. ISER, Rio de Janeiro.

Fernandes RC 1988. Sem fins lucrativos, pp. 8-23. In L Landim (org.). Sem fins lucrativos: as organizações não-governamentais no Brasil. ISER, Rio de Janeiro.

Galvão J 2000. Aids no Brasil: a agenda de construção de uma epidemia. ABIA, Rio de Janeiro; Editora 34, São Paulo.

Galvão J 2002a. 1980-2001: uma cronologia da epidemia de HIV/Aids no Brasil e no mundo. (Coleção ABIA, Políticas Públicas 2).

Galvão J 2002b. Brasil e acesso aos medicamentos para Aids: a saúde pública como uma questão de direitos humanos, pp. 239-247. In Rede Social de Justiça e Direitos Humanos. Direitos Humanos no Brasil 2002. Global Exchange, São Paulo.

Haddad S 2002 (org.). O N G e universidades: desafios para a cooperação na América Latina. Abong; Editora Fundação Peirópolis, São Paulo.

Landim L 1988 (org.). Sem fins lucrativos: as organizações não-governamentais no Brasil. ISER, Rio de Janeiro.
Landim L 1993. Para além do mercado e do Estado? Filantropia e cidadania no Brasil. ISER, Rio de Janeiro.

Landim L 2002. M últiplas identidades das ON Gs, pp. 17 50. In S Haddad (org.). ON G e universidades: desafios para a cooperação na América Latina. Editora Fundação Peirópolis, São Paulo.

M attos RA, Terto V \& Parker R 2001. As estratégias do Banco M undial ea resposta à Aids no Brasil. (Coleção ABIA, Políticas Públicas 1 ).

Oliveira F 2002. Entre a complexidade e o reducionismo: para onde vão as ON Gs da democratização? pp. 5162. In S. Haddad (org.). ONG e universidades: desafios para a cooperação na América Latina. Editora Fundação Peirópolis, São Paulo.

Oliveira M A, Santos EM \& M ello JM C 2001. Aids, ativismo e regulação de ensaios clínicos no Brasil: o Protocolo 028. Cadernos de Saúde Pública 17(4):863875.

Pereira LC \& Grau NC 1999. Entre o Estado e o mercado: o público não-estatal, pp. 15-48. In LC Pereira \& NC Grau NC (org.). 0 público não-estatal na reforma do Estado. Fundação Getúlio Vargas, Rio de Janeiro.

Ramos S 2002. M inorias e prevenção da violência, pp. 2740. Das políticas de segurança pública às políticas públicas de segurança. Ilanud, São Paulo.

Santos B S \& Avritzer L 2002. Para ampliar o cânone democrático, pp. 39-82. In BS Santos (org). Democratizar a democracia: os caminhos da democracia participativa. Civilização Brasileira, Rio de Janeiro.

Schumaher S\& Brazil EV (org.) 2000. Dicionário M uIheres do Brasil 2000. Jorge Zahar Editor, Rio de Janeiro.

Soares LE 2001. Notas sobre a problemática da segurança pública. IPEA. Políticas Sociais 2: 121-129.

Solano N 2000. As organizações não-governamentais e a Coordenação Nacional de DST/Aids. Direitos humanos, cidadania eAids. Cadernos Abong 28:75-130.

Teixeira ACC 2002. A atuação das organizações não-governamentais: entre o Estado e o conjunto da sociedade. In E Dagnino (org.). Sociedade civil e espaços públicos no Brasil. Editora Paz e Terra, São Paulo.

Venancio ATA 1990. Sobre a "nova psiquiatria" no Brasil: um estudo de caso do hospital-dia do Instituto de Psiquiatria. Dissertação de mestrado. Programa de PósGraduação em Antropologia Social, Universidade Federal do Rio de Janeiro, Rio de Janeiro.

Vieira L 2001. Os argonautas da cidadania: a sociedade civil na globalização. Editora Record, Rio de Janeiro.

Artigo apresentado em 8/8/2004

Aprovado em 5/9/2004

Versão final apresentada em 10/10/2004 